\title{
Vasopressin Tannate in Oil
}

National Cancer Institute

\section{Source}

National Cancer Institute. Vasopressin Tannate in Oil. NCI Thesaurus. Code C1552.

An oil based formulation of Vasopressin, which could be administered intramuscularly.

$(\mathrm{NCl})$ 